\title{
Movement, habitat utilization and behaviour of coral trout Plectropomus leopardus during and after the reproductive period on the southern Great Barrier Reef
}

\author{
C. M. Bunt ${ }^{1, *}$, M. J. Kingsford ${ }^{2}$ \\ ${ }^{1}$ Biotactic Fish and Wildlife Research (Biotactic, Inc) 691 Hidden Valley Road, Kitchener, Ontario N2C 2S4, Canada \\ ${ }^{2}$ School of Marine and Tropical Biology and ARC Centre of Excellence for Coral Reef Studies, James Cook University, \\ Townsville QLD 4811, Australia
}

\begin{abstract}
Coral trout Plectropomus leopardus (mean total length $=498.9 \pm 19.7 \mathrm{~mm}, \mathrm{n}=10$ ) were tagged and tracked with ultrasonic transmitters over $81 \mathrm{~d}$ at an intra-lagoonal location at One Tree Island, Great Barrier Reef, Australia $\left(23.4979^{\circ} \mathrm{S}, 152.0712^{\circ} \mathrm{E}\right)$. Movement and habitat preferences were compared during the transition between the reproductive and post-reproductive period. Overall, mean movement was highest between 05:00 and 10:00 h, with the most movement during the crepuscular period and the least movement at night. There was no difference in nighttime movement during or after the reproductive period. Mean daily movement $(14.48 \pm$ $\left.0.26 \mathrm{~km} \mathrm{~d}^{-1}\right)$ and fish depths $(4.23 \pm 0.02 \mathrm{~m})$ during the post-reproductive period were significantly greater than both movement $\left(10.63 \pm 0.13 \mathrm{~km} \mathrm{~d}^{-1}\right)$ and depths occupied $(3.38 \pm 0.01 \mathrm{~m})$ during the reproductive period, which was likely related to reallocation of bioenergetic resources to foraging related activities rather than spawning. Most fish movement was localized (within $0.04 \mathrm{~km}^{2}$ ), with some movements recorded outside of this area to a maximum distance of $0.6 \mathrm{~km}$. Fish traversed sand and small scattered coral out-croppings to reach areas of continuous reef. The ranges of movement and habitat preferences described in this study are important for future research on habitat requirements and behavioural changes across the transition period between reproductive and post-reproductive states. Furthermore, this study provides additional information that may be used for focusing and delineating species-specific Marine Protected Area management plans.
\end{abstract}

KEY WORDS: Plectropomus leopardus $\cdot$ Serranidae $\cdot$ Movement $\cdot$ Habitat preference $\cdot$ Habitat requirements · Ultrasonic telemetry $\cdot$ Marine Protected Area

\section{INTRODUCTION}

Common coral trout Plectropomus leopardus are epinephiline serranids (i.e. groupers) that form the basis of the commercial and recreational reef line fishery on the Great Barrier Reef (Russ 1991), and comprise $35-55 \%$ of the commercial catch, $20-25 \%$ of the charter catch and $15-20 \%$ of the recreational catch (Mapstone et al. 2004). In Queensland, Australia, alone, the $P$. leopardus fishery generates approximately \$35 million (AUD) in gross annual revenue
(Queensland Government 2011). However, previous studies have revealed evidence of population decline of this economically valuable species (Fulton et al. 1999, Morris et al. 2000, Graham et al. 2003, Little et al. 2005), and $P$. leopardus are now classified by the IUCN as Near Threatened (Cornish \& Kiwi 2004).

Declines in Plectropomus leopardus populations have been attributed to life history patterns of the species (Bohnsack 1982, Russ 1991), specifically their tendency to form reproductive aggregations (Thresher 1984), which make them vulnerable to 
overfishing (Samoilys 1997a). In the last $20 \mathrm{yr}$, the establishment of marine reserves in known $P$. leopardus aggregation locations has been identified as the most viable strategy for sustainable management of this species (DeMartini 1993, Rowley 1994, Russ \& Alcala 1996a,b). Management programs designed to protect specific $P$. leopardus reproduction aggregation areas are more likely to succeed as additional information on reproductive behaviour, movement and habitat requirements becomes available (Zeller 1996, 1997, 1998, Samoilys 1997a,b, Zeller \& Russ 1998).

In addition to fisheries-related economic implications, the sustainability of Plectropomus leopardus populations has ecological ramifications. This species feeds on fishes and invertebrates (Choat 1968, Kingsford 1992, St. John et al. 2001), and thereby influences mortality rates and population dynamics of other predators and their prey (Hixon 1991, Connell \& Kingsford 1998, Mclean et al. 2011). Data on spatial and temporal scales of movement as well as habitat selection and habitat preferences of these higherorder predators are important for reef fisheries management and the maintenance of viable $P$. leopardus populations, and have implications for the balance of the entire reef ecosystem (Sluka et al. 1994, Ceccarelli \& Ayling 2010).

Previous studies on Plectropomus leopardus spatial utilization have focused on counting individuals in aggregations, mapping aggregation sites (AguilarPerera \& Aguilar-Dávil 1996, Samoilys 1997a) and enumerating intra-reef patterns of abundance (Connell \& Kingsford 1998, Kingsford 2009). Habitat preferences and movement patterns during the reproductive and post-reproductive transition at aggregation sites are largely unknown.

Ultrasonic telemetry has been used with Plectropomus leopardus to determine the movement within home ranges (Zeller 1997), spawning aggregations (Zeller 1998) and across boundaries of Marine Protected Areas (MPAs) (Zeller \& Russ 1998). However, data from these studies were not stratified to allow movement comparisons during reproductive and post-reproductive periods. Therefore, the purpose of this project was to enhance and build on previously acquired information by providing detailed data to: (1) characterize diel movement patterns (in 3 dimensions) of $P$. leopardus into and out of an aggregation site during the reproductive (November-December) and post-reproductive periods (January-February); and (2) evaluate diel habitat utilization patterns and habitat preferences during the reproductive and postreproductive periods.

\section{MATERIALS AND METHODS}

\section{Study site and sampling design}

Plectropomus leopardus were collected, tagged and tracked at One Tree Island (OTI), southern Great Barrier Reef, Australia $\left(23.4979^{\circ} \mathrm{S}, 152.0712^{\circ} \mathrm{E}\right.$; Fig. 1a). The tracking location was based on longterm SCUBA observations over 13 yr that identified an area with a pre-existing and presumably spawning-related aggregation site. Fish were monitored over $81 \mathrm{~d}$ from 13 November 2001 to 4 February 2002, spanning the typical reproductive (NovemberDecember) and post-reproductive (January-February) periods at OTI (M.J.K., pers. obs.). These periods are estimates based on definitions of reproductive periodicity by Domeier \& Colin (1997) because the beginning and ending dates of spawning are usually not known for certain. However, there was distinct evidence that fish were in a reproductive state at the beginning of the study. This evidence included: unusual aggregation behaviour of mature fish (see Pet et al. 2005) during a time of the year when spawning of this species is known to occur; swollen gonads in females; and males that expressed milt on Analytical groups in this study did not contain fish from both reproductive states, and no data were included in the analyses from 18 December 2001 to 11 January 2002. This unintended but surreptitious buffer was the result of technical difficulties with the tracking system during a period when researchers were away from OTI. We euthanised one of the tagged fish (4591) on 18 January 2002 and there were no gametes present internally, suggesting that spawning was complete. It is unlikely that this was an immature fish, based on behavioural comparisons with other similarly sized mature fish in the spawning aggregation in November/December.

\section{Fish tagging and tracking}

Plectropomus leopardus were collected from the aggregation by precision angling, which involved the presentation of a pilchard to target fish by a diver who minimized entanglement of gear with coral, as an angler on a boat retrieved the hooked fish. These fish were then measured and anaesthetized with a 50 to $75 \mathrm{ppm}$ solution of clove oil and ethanol. A depth-sensitive ultrasonic transmitter (VEMCO, 106 $\times 15 \mathrm{~mm}$ with a $2 \mathrm{~s}$ burst rate) was implanted into the body cavity through a $15 \mathrm{~mm}$ incision posterior to the left pelvic fin. The incision was closed with 2 simple 
a)

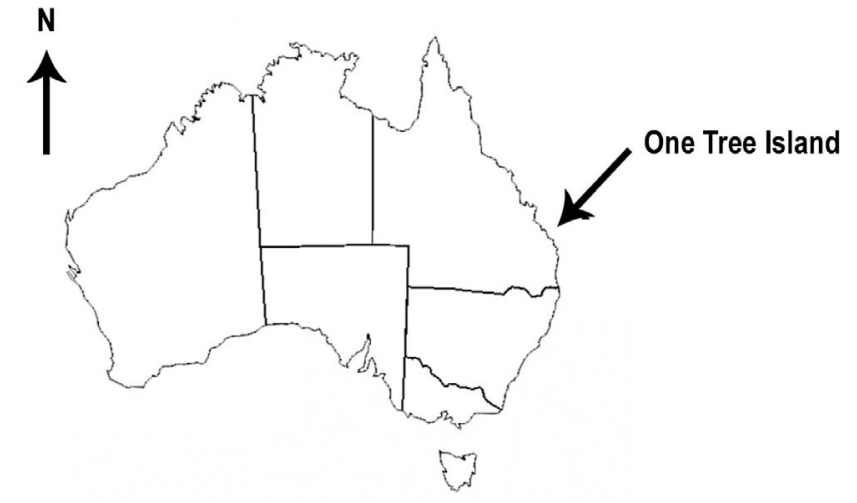

b)

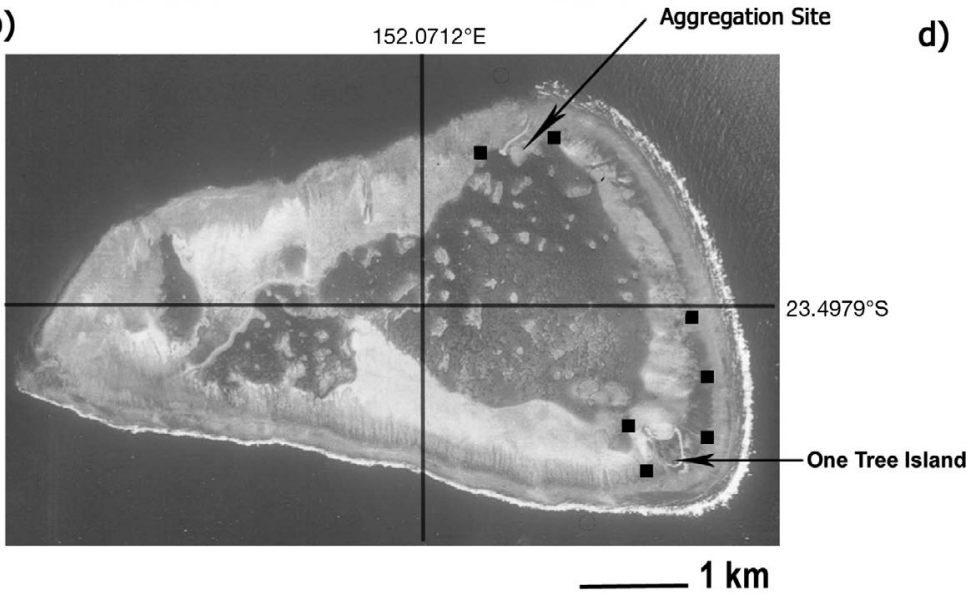

c)

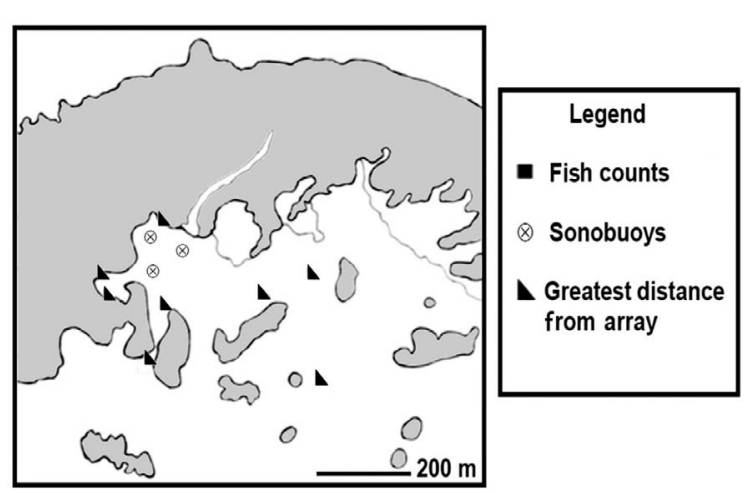

d)

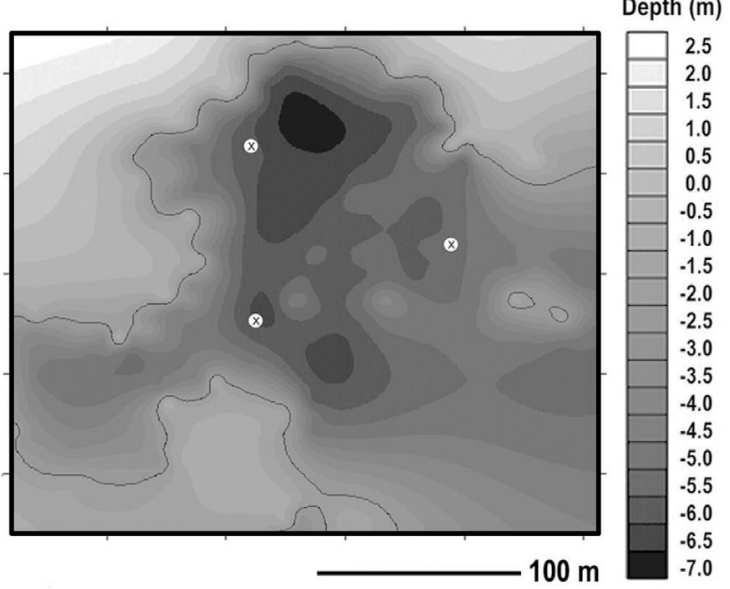

Fig. 1. (a) The approximate location of One Tree Island (OTI) on the Southern Great Barrier Reef. (b) OTI lagoon (14 km²), showing the aggregation site and fish count locations. (c) Aggregation area, with approximate positions of VRAP sonobuoys used to track Plectropomus leopardus and maximum distances fish moved from the array. (d) Enlargement of the aggregation site, showing tracking buoys and depth contours at high tide

interrupted braided silk sutures. Tagged fish were placed in flow-through pens for a recovery period of 3 to $6 \mathrm{~h}$, and were then released near the site of original capture. Fish tracking was conducted with a radio-linked acoustic positioning sonobuoy array (VRAP System, Vemco) $1.5 \mathrm{~km}$ northwest of the OTI research station. Tracking system function and triangulation of transmitters is described in $\mathrm{O}^{\prime}$ Dor et al. (2001). According to the manufacturer and verified with pre-study tests, locations were accurate to within $1 \mathrm{~m}(x, y$ dimensions) and depth data were accurate to within $0.2 \mathrm{~m}$ when transmitters were not hidden behind coral. During collection of VRAP data, telemetry data from areas outside the array were also recorded by boat using mobile VEMCO VR-60 receivers and a towed hydrophone. On occasion we used an underwater pinger locator (VEMCO VR-96) to track fish within the aggregation site with SCUBA. Plectropomus leopardus were also counted with SCUBA at the aggregation site and at 6 other sites along the lagoon edge to determine how representa- tive the tagging site was (Kingsford 1992, 2009). Sites were separated by 0.3 to $5 \mathrm{~km}$ along the edge of the lagoon (Fig. 1b). At each site, fish were counted in 5 transects, each measuring $5 \times 25 \mathrm{~m}$. This sampling design was repeated January-February each year from 1995 to 2007.

\section{Movement and depths}

All fish were simultaneously tracked within a $0.04 \mathrm{~km}^{2}$ area within the OTI lagoon. Distances (m) between successive time-stamped locations were calculated from filtered telemetry data. Approximately $1 \%$ of movement data appeared to be related to signal bounces and erroneous reception based on visual examination of temporal and spatial aspects of the telemetry data. These data points were removed accordingly to minimize overestimates of movement. Plectropomus leopardus movement data were analyzed within and among 4 daily time periods (early 
morning: 05:00:01-10:00:00 $\mathrm{h}_{\text {; }}$ midday: 10:00:01-

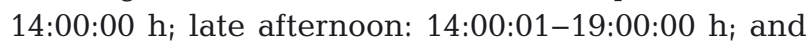
night: 19:00:01-05:00:00 h) during and after the typical reproductive period. Movement patterns as well as fish depths were analyzed using $t$-tests and a 3factor general linear ANOVA with the factors defined as individual, time block (time of day) and spawning state (reproductive/post-reproductive).

\section{Habitat mapping}

A bathymetric map of the study site was developed using a combination of SONAR and differential GPS (Fig. 1d). Maps of physical habitat (coral, open sand, rubble substrate, coral formations or bommies) were created throughout the study period. Coral was identified to genus and species (when possible) and mapped over scaled images derived from the bathymetric map of the reef edge. After the telemetry study was complete, habitat within the study area was mapped using SCUBA. To create scaled maps of habitat availability, we used a novel technique with an acoustically-tagged diver and an assistant, who both tabulated substrate and coral along underwater transects (spaced approximately $3 \mathrm{~m}$ within the tracking array) while being tracked with the telemetry system. In this way it was possible to create a scaled map of habitat availability that could be superimposed on a similarly scaled map of fish movement for analysis.

Raw telemetry data were filtered and superimposed over maps of habitat availability using a Windows-based telemetry data analysis program called Biotrek, which was custom designed for this study. This software used pixel-coding to assign specific habitat characteristics on scaled maps, and then correlated pixel codes with locations occupied by fish when they were tracked. The program essentially recreated patterns of habitat/depth utilization by replaying scaled paths of movement over scaled maps of habitat in areas that fish occupied. The program calculated habitat utilization histograms related to the number of observations of each fish in each habitat category.

Total area and percentage of the total area for each habitat type was calculated using GE path v 1.4.6. Habitat preference was calculated by dividing habitat utilization by habitat availability, which was then standardized to a value of 1 by dividing by the highest preference value (Mäki-Petäys et al. 1997) for each respective time block across the reproductive and post-reproductive periods. Patterns related to habitat utilization throughout the day and night during and after the reproductive period were analyzed with a $G$-test. All analyses $(\alpha=0.05)$ were conducted using JMP 7.0 (SAS Institute).

\section{RESULTS}

\section{Movement}

Tagged fish from the aggregation site slowly began to disappear from the OTI lagoon over the course of the study, which corresponded to the transition between the estimated reproductive and post-reproductive periods (Table 1). Of the 10 fish that were tagged in November 2001, Fish 4587 was last detected on 11 December 2001 and Fish 4590 was not detected after 18 January 2002, despite extensive mobile tracking efforts throughout and around OTI. By 31 January 2002, only $40 \%$ of tagged Plectropomus leopardus were located near the aggregation site.

Fish were absent from the array for more than an hour before returning to the aggregation on 5 occasions during the reproductive period and 45 occasions after reproduction (Table 1). Fish detected outside the lagoon moved to a maximum distance of $593 \mathrm{~m}$ from the aggregation (Fig. 1c). Some fish disappeared and reappeared periodically from the array area, indicating movements away from the aggregation site (verified using mobile tracking). Other fish used complex areas of coral habitat, and transmitter signals were undetectable even while they were in the array (as determined with SCUBA and portable underwater receivers), particularly during the reproductive period. Movement outside the array increased during the post-reproductive period as the aggregation began to disperse in late January (Table 1).

Plectropomus leopardus movement for all daily time segments combined increased significantly after the reproductive period $(F=121.65, \mathrm{p}<0.0001$; Table 2 , Figs. 2, 3a, c,e). During the reproductive period, mean daily movement was $10.63 \pm 0.13 \mathrm{~km} \mathrm{~d}^{-1}$; after reproduction, mean daily movement was $14.48 \pm 0.26 \mathrm{~km}$ $\mathrm{d}^{-1}$ (Fig. 2). The greatest movement occurred during crepuscular hours, and particularly in the morning both during (12.29 $\pm 0.17 \mathrm{~km} \mathrm{~d}^{-1}$; Table 3) and after the reproductive period $\left(17.14 \pm 0.51 \mathrm{~km} \mathrm{~d}^{-1}, t=10.01\right.$, $\mathrm{p}<0.0001$; Table 3). P. leopardus moved the least at night, and there was no difference in nighttime movement during the reproductive period $(7.99 \pm 0.16 \mathrm{~km}$ $\mathrm{d}^{-1}$; Table 3) or after the reproductive period (7.77 \pm $0.24 \mathrm{~km} \mathrm{~d}^{-1}, t=-0.55, \mathrm{p}=0.58$; Table 3, Fig. 2). 


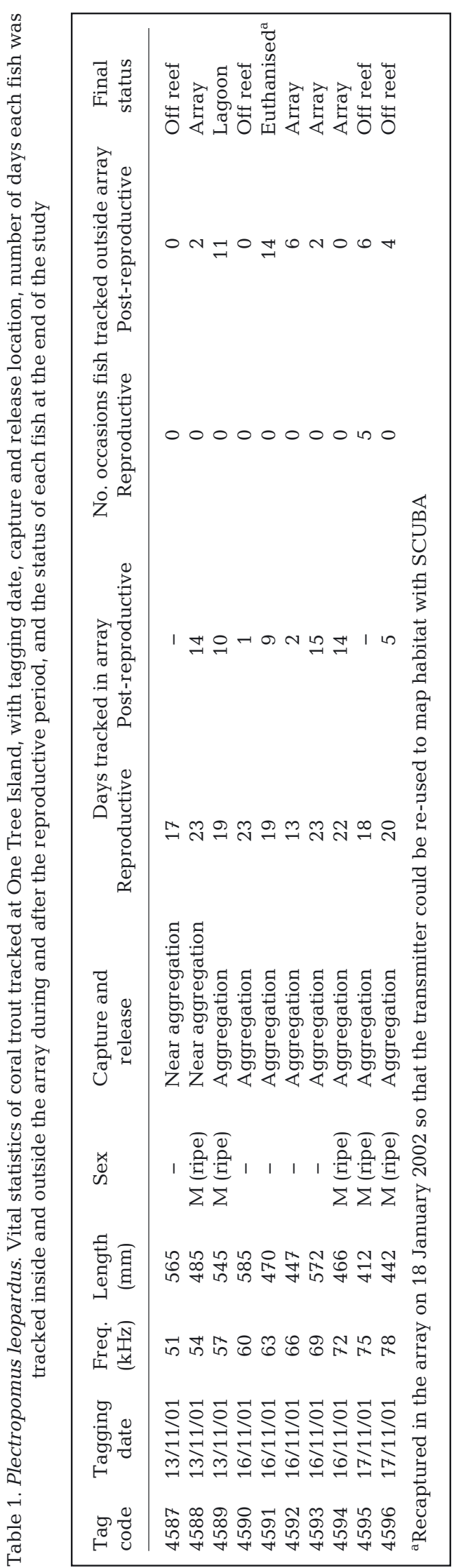

\section{Depth}

The maximum depth of the study area was $7.5 \mathrm{~m}$ at high tide, and fish utilized almost the entire depth range. The mean depth occupied during the reproductive period $(3.38 \pm 0.01 \mathrm{~m})$ was significantly shallower than the mean depth occupied during the post-reproductive period, $4.23 \pm 0.02 \mathrm{~m}(F=1093.37$, $\mathrm{p}<0.0001$; Table 2, Table 3, Figs. 2, 3b,d,f, 4). Fish occupied deeper areas during the reproductive period at night, and the shallowest depths were occupied in the morning and afternoon. After the reproductive period, the opposite pattern was observed. Despite overall trends, tracks of individual fish indicated that there was a great deal of variation, with some fish making rapid changes in depth in the water column $(>6 \mathrm{~m})$, while other fish tended to maintain similar depths throughout the day and night (Fig. 4).

Vertical positions of Plectropomus leopardus in the water column were variable but did not appear to be influenced by daily tidal conditions during or after the reproductive period. OTI, including the area where the study was conducted, is a ponding lagoon, so the water level remains elevated and stable as sea level drops outside the reef. As such, the tidal fluctuation (for low tide) is truncated in the intralagoonal location where the tracking study took place. This confounds any statistical analyses designed to demonstrate that the fish responded to tidal fluctuations. Fig. 4 shows that as water elevation (or tide level) decreases, fish tended to occupy shallower areas; however, we believe that this is an artifact resulting from reduced hydrostatic pressure on the tag transducer rather than vertical movement in the water column. This also makes sense in light of the highly territorial nature of coral trout. Therefore, based on qualitative observations, $P$. leopardus tended to remain at specific locations relative to the bottom of the reef and did not appear to be affected by changes in surface water elevation (Fig. 4).

\section{Habitat}

Habitat was not distributed uniformly throughout the study area, and habitat utilization was not uniform throughout the day during or after the reproductive period ( $G$-test, $G=14.94$, all $\mathrm{p}<0.0001$ ). Sand was the most abundant habitat type (43\%) and was utilized more than any other habitat type during the reproductive $(36 \%)$ and post-reproductive periods (38\%; Table 4, Fig. 5). However, in terms of pref- 
Table 2. 3-factor ANOVA comparing movement and depth utilization throughout the day (time period) during and after the reproductive period (spawning status)

\begin{tabular}{|lcrrc|}
\hline Factor & df & SS & \multicolumn{1}{c|}{$F$} & $p$ \\
\hline Movement & & & & \\
Spawning status & 1 & 32850.71 & 121.65 & $<0.0001$ \\
Time period & 3 & 86990.54 & 107.38 & $<0.0001$ \\
Individual & 9 & 51386.29 & 21.14 & $<0.0001$ \\
& & & & \\
Depth & & & & \\
Spawning status & 1 & 1894.26 & 1093.37 & $<0.0001$ \\
Time period & 3 & 1001.45 & 192.68 & $<0.0001$ \\
Individual & 9 & 21656.83 & 1388.93 & $<0.0001$ \\
\hline
\end{tabular}

Table 3. $t$-tests comparing movement and depth utilization throughout the day (time period) during and after the reproductive period. Movement, depth and estimate are mean $( \pm \mathrm{SE})$

\begin{tabular}{|c|c|c|c|c|c|}
\hline & $\begin{array}{l}\text { Movement (kn } \\
\text { Reproductive }\end{array}$ & $\begin{array}{l}\left.\mathrm{d}^{-1}\right) \text {, or depth }(\mathrm{m}) \\
\text { ost-reproductive }\end{array}$ & Estimate & $t$ & $\mathrm{p}$ \\
\hline \multicolumn{6}{|l|}{ Movement } \\
\hline Night & $7.99 \pm 0.16$ & $7.77 \pm 0.24$ & $-0.11 \pm 0.20$ & -0.55 & 0.58 \\
\hline Early morning & $12.29 \pm 0.17$ & $17.14 \pm 0.51$ & $2.42 \pm 0.24$ & 10.01 & $<0.0001$ \\
\hline Midday & $10.98 \pm 0.22$ & $16.38 \pm 0.49$ & $2.70 \pm 0.24$ & 11.35 & $<0.0001$ \\
\hline Late afternoon & $11.91 \pm 0.35$ & $15.03 \pm 0.45$ & $1.56 \pm 0.33$ & 4.78 & $<0.0001$ \\
\hline \multicolumn{6}{|c|}{ Depth utilization } \\
\hline Night & $3.69 \pm 0.02$ & $3.91 \pm 0.04$ & $0.11 \pm 0.03$ & 3.99 & $<0.0001$ \\
\hline Early morning & $3.23 \pm 0.02$ & $4.38 \pm 0.04$ & $0.58 \pm 0.02$ & 23.44 & $<0.0001$ \\
\hline Midday & $3.28 \pm 0.02$ & $4.25 \pm 0.03$ & $0.48 \pm 0.02$ & 19.53 & $<0.0001$ \\
\hline Late afternoon & $3.21 \pm 0.03$ & $4.31 \pm 0.03$ & $0.55 \pm 0.02$ & 23.05 & $<0.0001$ \\
\hline
\end{tabular}

erence, live Porites coral, followed by large ( $>2 \mathrm{~m}$ wide, $>1 \mathrm{~m}$ high) bommies, ranked as the most important habitat type during the reproductive period, regardless of time of day (Fig. 5a,c,e,g, Table 4). After spawning, there was a shift in habitat preference that varied depending on the time of day. At night, Plectropomus leopardus preferred to use coral rubble, whereas in the early morning they preferred large bommies $>2 \mathrm{~m}$ wide and $>1 \mathrm{~m}$ high. At night and in the late afternoon they preferred smaller bommies, 1 and $2 \mathrm{~m}$ wide and $>0.5 \mathrm{~m}$ high (Fig. 5b,d,f,h).

\section{Patterns of abundance}

Twenty Plectropomus leopardus were observed near or within the aggregation area by SCUBA on 15 November 2001. Nine P. leopardus were observed together in an area measuring only $\sim 1 \mathrm{~m}^{2}$. The abundance of fish found at the aggregation site during the study was typical of previous years. Average density at the aggregation site was higher than the average density for all 7 sites along the edge of the lagoon. Fewer P. leopardus were counted throughout the lagoon from 2002 to 2004 (Fig. 6). This decrease
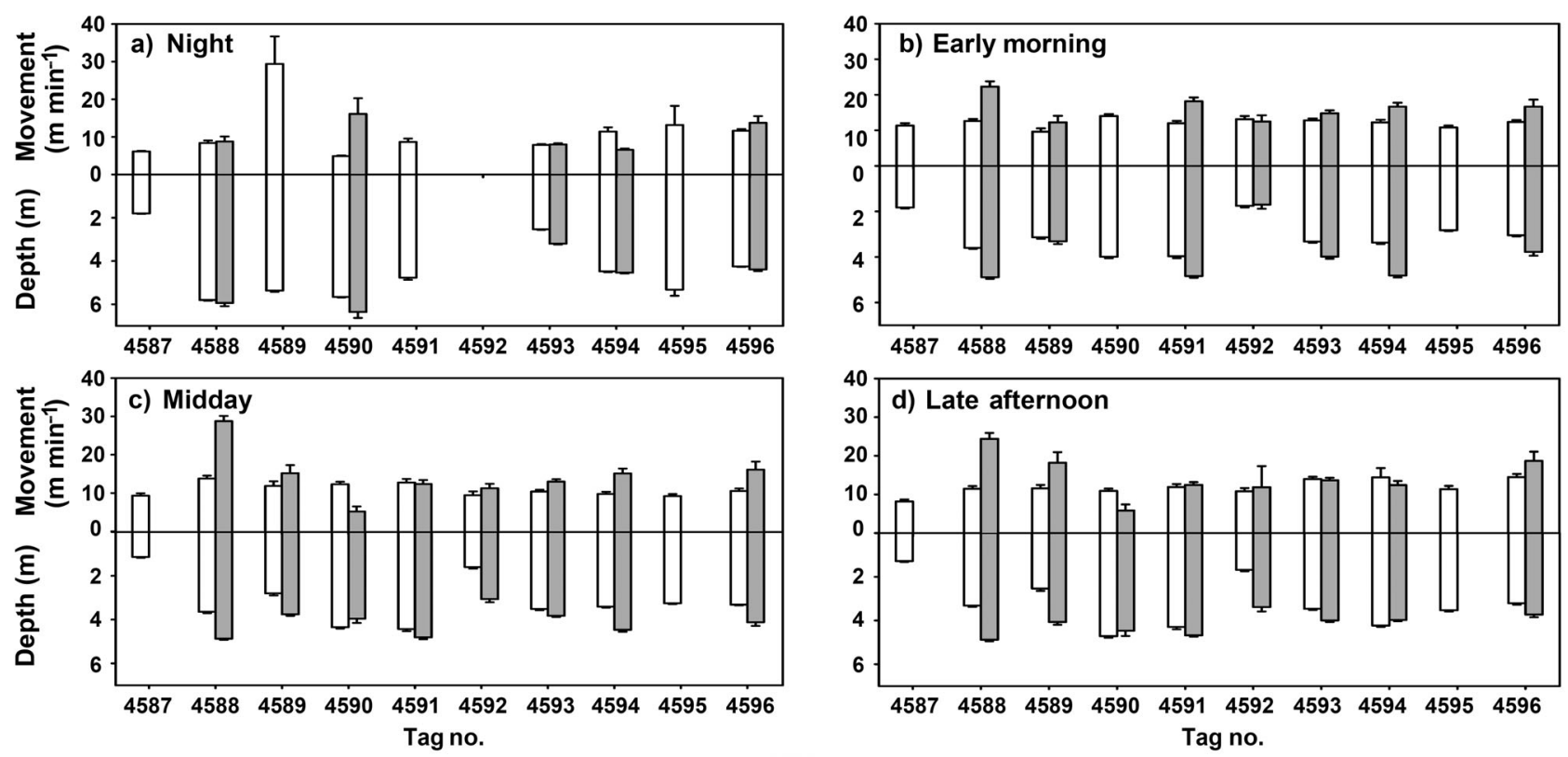

Fig. 2. Plectropomus leopardus. Mean movement $( \pm \mathrm{SE})$ and mean depth utilization $(\mathrm{SE})$ of coral trout during the reproductive period (white, November-December 2001) and after the reproductive period (grey, January-February 2002) across all daily time periods near the aggregation site 

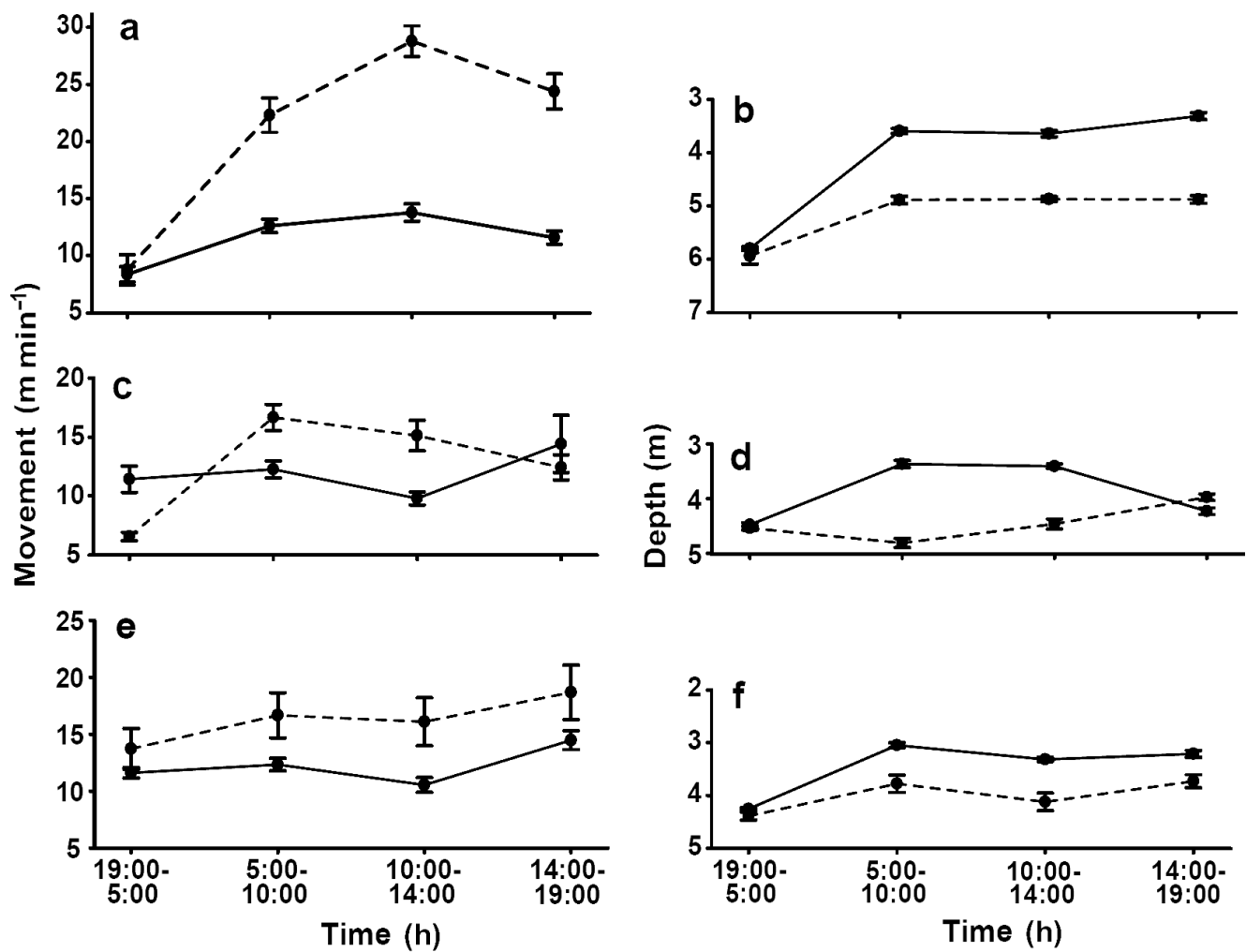

Fig. 3. Plectropomus leopardus. Detailed examples of $(\mathrm{a}, \mathrm{c}, \mathrm{e})$ mean movement $( \pm \mathrm{SE})$ and $(\mathrm{b}, \mathrm{d}, \mathrm{f})$ mean depth $( \pm \mathrm{SE})$ of Individuals $4588(\mathrm{a}, \mathrm{b}), 4594(\mathrm{c}, \mathrm{d})$ and $4596(\mathrm{e}, \mathrm{f})$ within the aggregation site during the reproductive period (solid line, NovemberDecember 2001) and after the reproductive period (dashed line, January-February 2002)

in abundance appeared to be related to loss of live coral cover that followed strong El Niño conditions in 1998 and 2001.

\section{DISCUSSION}

MPAs and fishing restrictions are essential for the recovery and sustainability of Plectropomus leopar$d u s$ and other serranids that are heavily targeted and exploited in the Indo-Pacific and the Great Barrier Reef (Williams et al. 2008). There is ample evidence that MPAs replenish fish populations (Graham et al. 2003, Nardi et al. 2004, Williamson et al. 2004, Watson et al. 2007, Russ et al. 2008) and are a promising global fisheries management option. Despite concerns of economic consequences associated with sequestering reef habitats for the sole purpose of conservation (Russ 1991), recent work has shown no net loss in revenue in commercial fisheries, with the losses of some fishers balanced by the gains of others (Jeffrey et al. 2012).

Identification of preferred habitats, movement capabilities and site fidelity within both home ranges and aggregation sites must be considered during de- lineation of MPAs, and should be a focus of conservation objectives. Although data are limited for most species, it is important to determine whether Plectropomus spp., as well as other serranids, can be effectively managed using multi-species rather than speciesspecific conservation strategies.

In this study, Plectropomus leopardus moved significantly greater distances, utilized significantly deeper habitat and preferred different habitat during the post-reproductive compared with the reproductive period. In comparison with other studies on P. leopardus, the intralagoonal site at OTI is somewhat unique within the Great Barrier Reef. This location is at the southern end of the P. leopardus distribution, and as such, the data collected for this study may be more relevant to southern populations than northern ones, and may partially explain differences in behaviour considering that the tracking methods that we used were similar to those used by Zeller (1996), Zeller \& Russ (1998) and Samoilys (1997a). Large amounts of data are typically collected with these types of VRAP telemetry projects, and this may have resulted in inflated distances moved due to the cumulative effect of minor signal bounces or variation in signal transmission. However, it is important to note that most of 

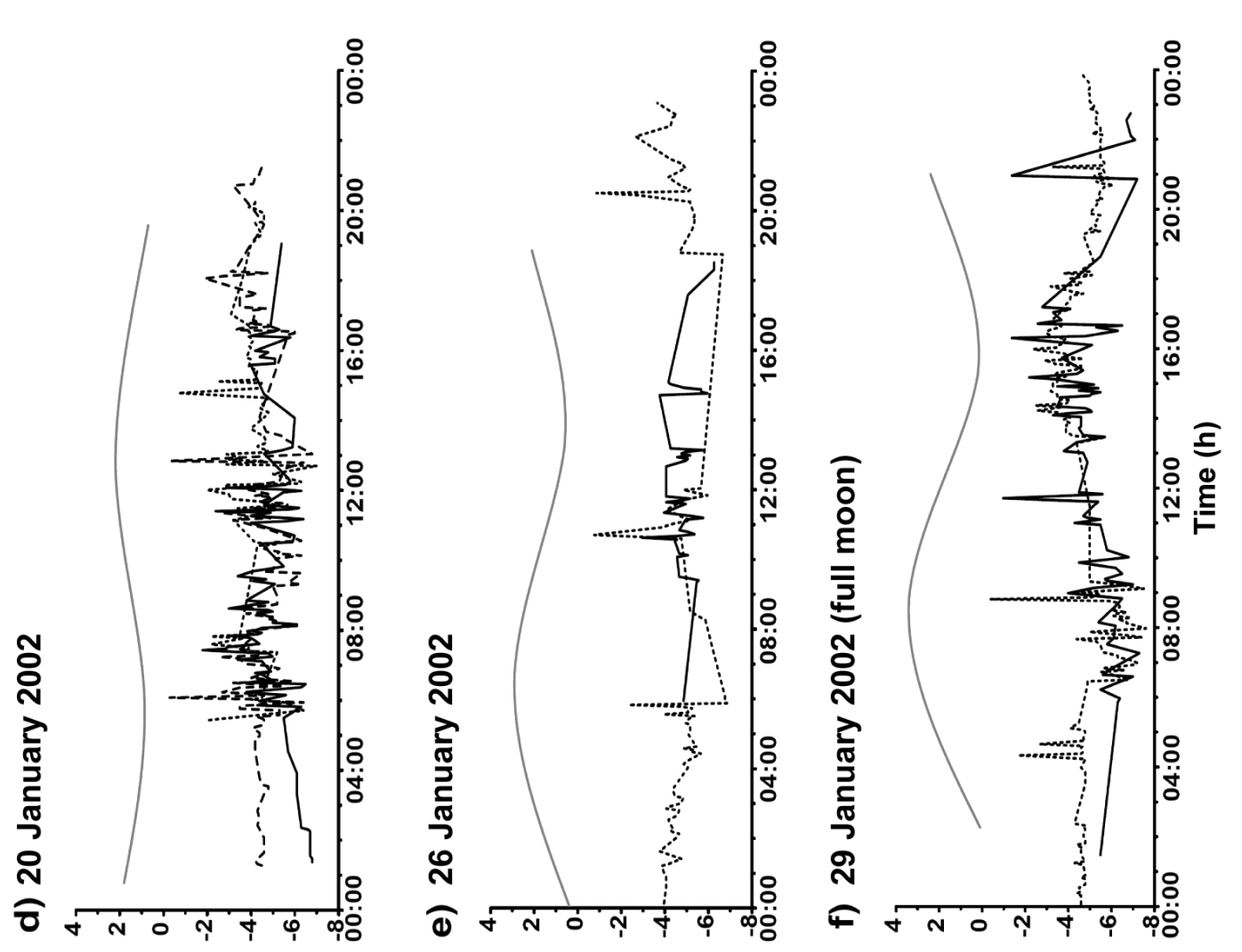

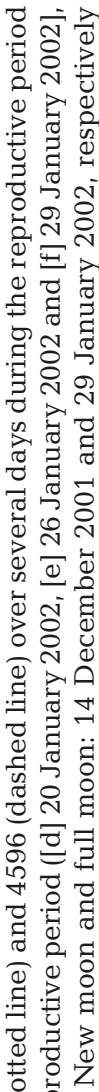

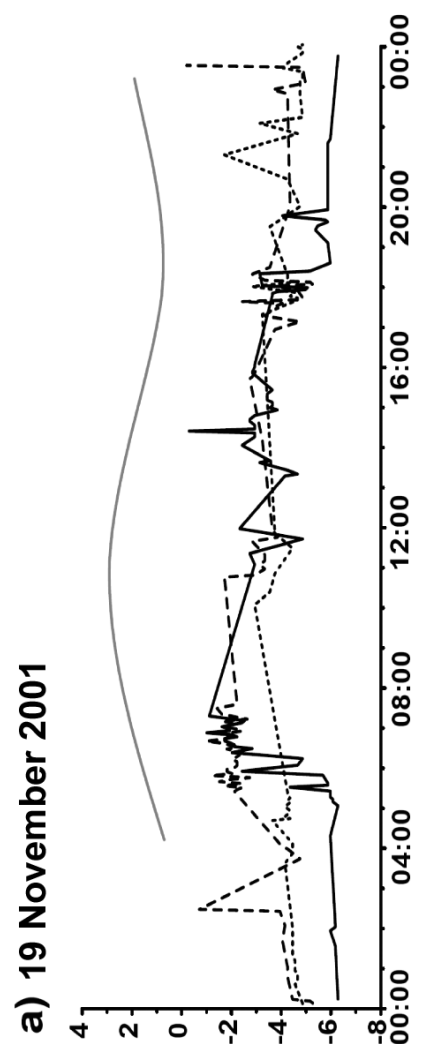

(u) पłdəa

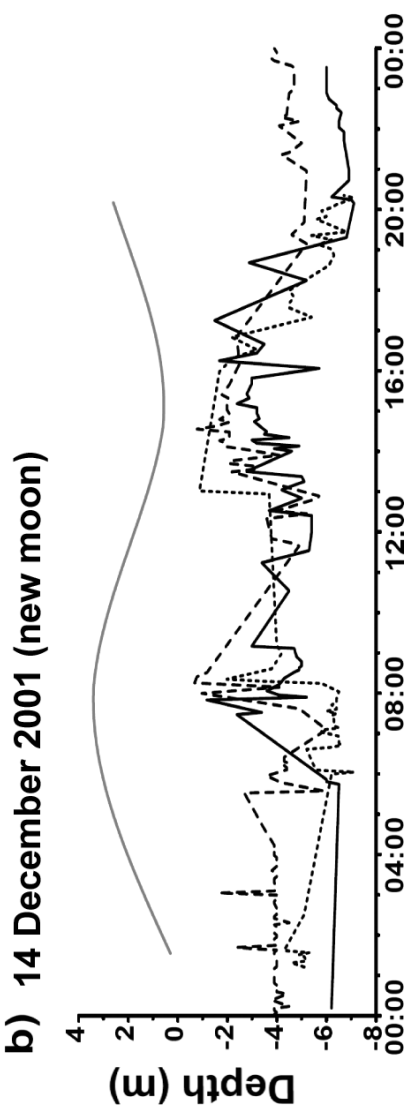

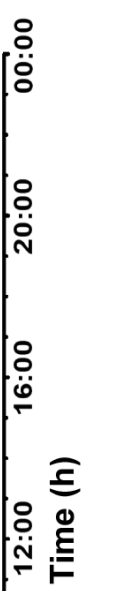

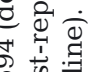

is

ब릴

훙ㅎㅇ

용

学范

용

○

空

它䜦

घี ซี

可

$\pi \frac{\pi}{7} \pi$

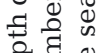

월

宅空

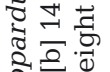

类

范:

¿

당ㅇ

응

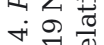


Table 4. Habitat type, number of sites surveyed, total area and percentage of total area of each habitat type within the receiver array, as well as coral trout utilization of each habitat type pooled across daily time blocks during and after the reproductive period

\begin{tabular}{|c|c|c|c|c|c|}
\hline \multirow[t]{2}{*}{ Habitat/substrate type } & \multirow[t]{2}{*}{ Number of sites } & \multirow[t]{2}{*}{ Total area $\left(\mathrm{m}^{2}\right)$} & \multirow[t]{2}{*}{$\%$ Available } & \multicolumn{2}{|c|}{ Habitat utilization (\%) } \\
\hline & & & & Reproductive & Post-reproductive \\
\hline Sand & 276 & 16803 & 43 & 36 & 38 \\
\hline Rubble & 118 & 7163 & 19 & 17 & 27 \\
\hline Live Porites coral & 85 & 5304 & 14 & 27 & 14 \\
\hline Bommie $^{\mathrm{a}}>2 \mathrm{~m}$ wide, $>1 \mathrm{~m}$ high & 27 & 1626 & 4 & 8 & 7 \\
\hline Bommie $1-2 \mathrm{~m}$ wide, $<0.5 \mathrm{~m}$ high & 23 & 1394 & 4 & 3 & 6 \\
\hline Bommie $1-2 \mathrm{~m}$ wide, $>0.5 \mathrm{~m}$ high & 33 & 2013 & 5 & 3 & 3 \\
\hline Bommie $<1 \mathrm{~m}$ wide, $<0.5 \mathrm{~m}$ high & 72 & 4414 & 11 & 6 & 5 \\
\hline Total & 634 & 38717 & 100 & 100 & 100 \\
\hline
\end{tabular}
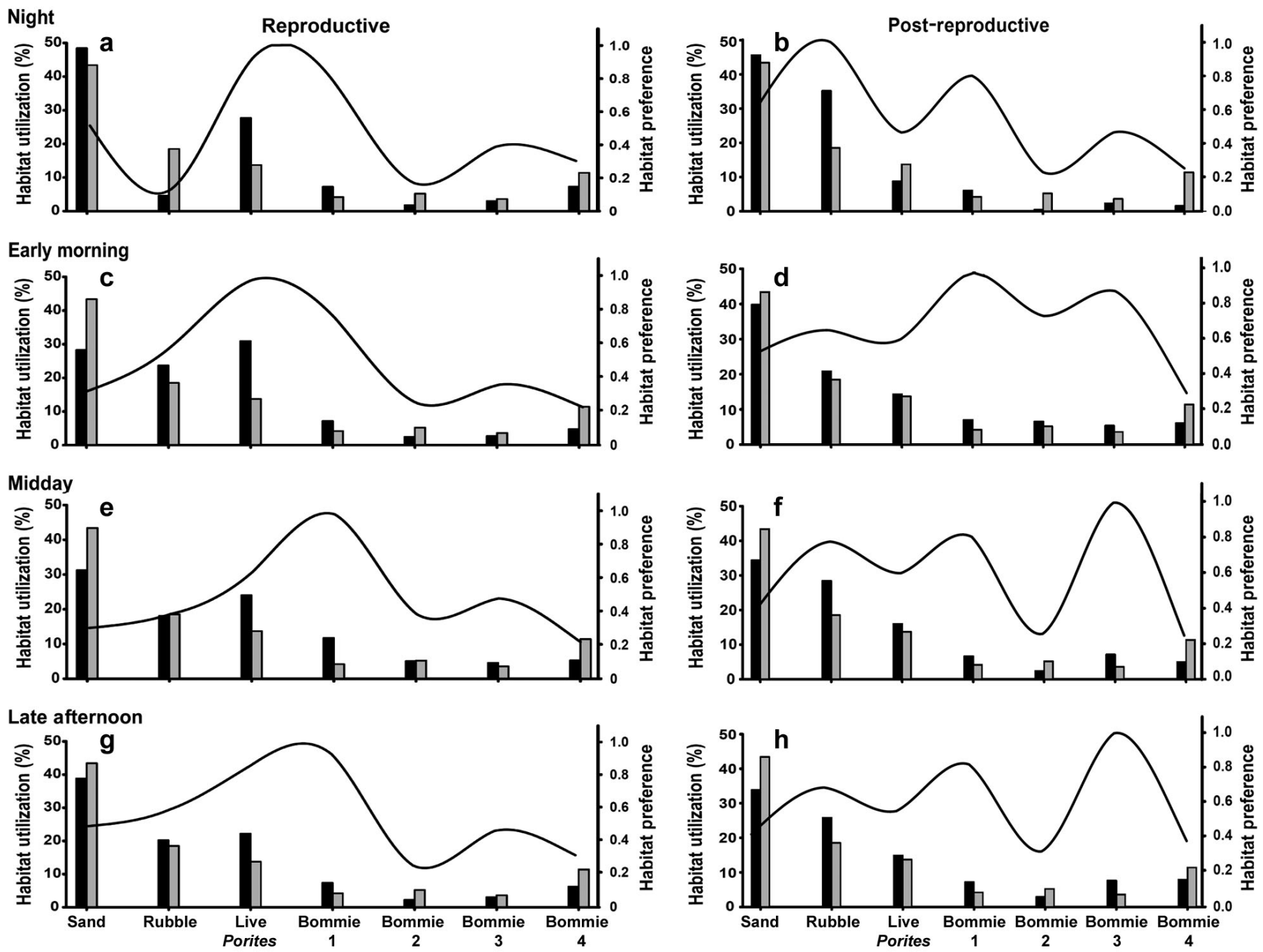

Fig. 5. Plectropomus leopardus. Habitat utilization (black bars), habitat availability (grey bars) and habitat preference curves for coral trout during the $(\mathrm{a}, \mathrm{b})$ night, $(\mathrm{c}, \mathrm{d})$ early morning, $(\mathrm{e}, \mathrm{f})$ midday and $(\mathrm{g}, \mathrm{h})$ late afternoon, during the reproductive period $(\mathrm{a}, \mathrm{c}, \mathrm{e}, \mathrm{g})$ and post-reproductive period $(\mathrm{b}, \mathrm{d}, \mathrm{f}, \mathrm{h})$. Bommie habitat types are as follows: Bommie $1:>2 \mathrm{~m}$ wide, $>1 \mathrm{~m}$ high;

Bommie 2: 1-2 $\mathrm{m}$ wide, $<0.5 \mathrm{~m}$ high; Bommie 3: 1-2 $\mathrm{m}$ wide, $>0.5 \mathrm{~m}$ high; and Bommie $4:<1 \mathrm{~m}$ wide, $<0.5 \mathrm{~m}$ high 


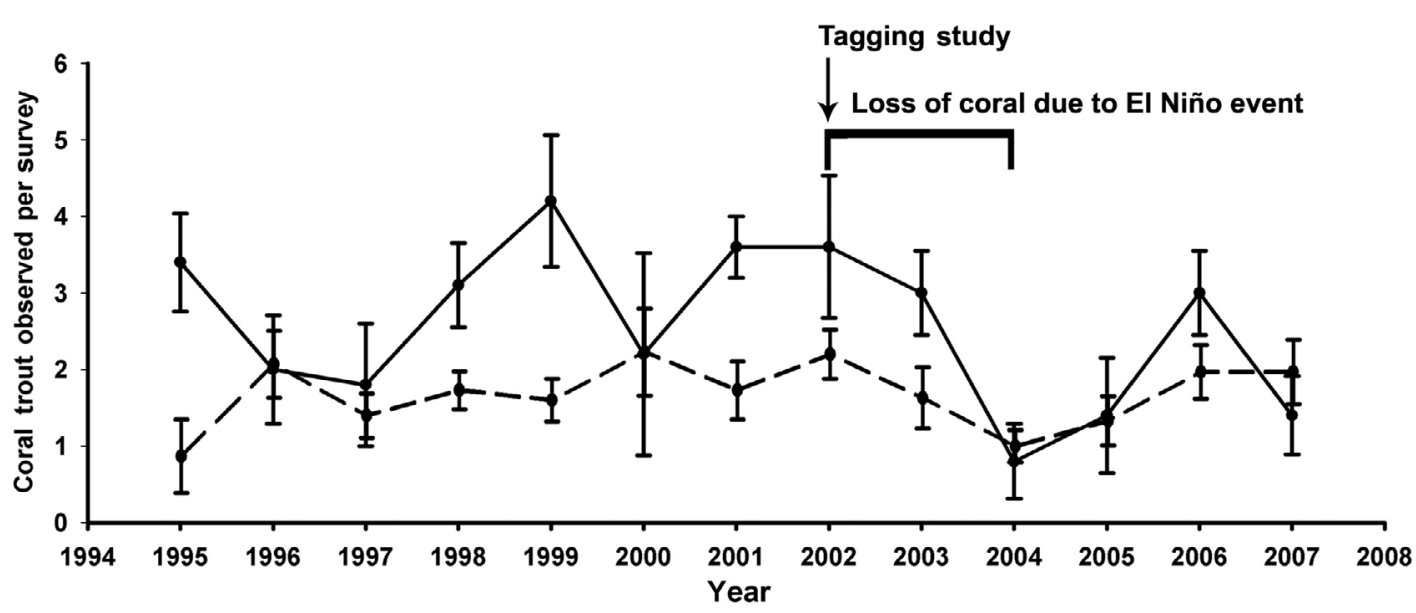

Fig. 6. Plectropomus leopardus. Changes in January abundance of coral trout observed per $125 \mathrm{~m}^{2}$ at One Tree Island from SCUBA counts (1995-2007). Solid line: mean $( \pm$ SE) number of observations near the lagoon aggregation; dashed line: mean $( \pm \mathrm{SE})$ number of observations at all other count sites combined (count locations shown in Fig. 1)

the potential biases in our data would have been consistent across the 2 periods (reproductive and postreproductive), and therefore the relative differences that we observed are significant and inferentially valuable. Despite the caveats, the differences in movement and habitat preferences between reproductive and post-reproductive periods from this study complement previously documented patterns and trends of $P$. leopardus behaviour that are essential for the development of effective management strategies.

As with many other species in the grouper family, this study showed that Plectropomus leopardus use a mosaic of habitats such as sand, rubble, live coral and bommies of varying dimension (Syms \& Kingsford 2008). They also use lagoon reef environments including reef slope, areas of strong water currents (Kingsford 1992, 2009) and live coral such as Acropora and Porites (Morris et al. 2000, Manson et al. 2005). The preference for live corals was evident at the aggregation site, particularly during the reproductive period, as also described by Connell \& Kingsford (1997). However, after reproduction, a shift away from live coral was noted at small spatial scales, with an increase in the use of coral rubble. This trend has also been documented for other heavily exploited and potentially threatened species such as black grouper Mycteroperca bonaci in Florida (Eklund et al. 2000), Nassau grouper Epinephelus striatus in the Bahamas (Eggleston 1995, Sadovy \& Eklund 1999, Bolden 2000), red hind E. guttatus in the US Virgin Islands (Nemeth 2005), Cephalopholis urodeta in the Indo-West Pacific (Donaldson 2002) and $P$. areolatus, $P$. lavevis and $P$. maculatus on the Great Barrier Reef (Hutchinson \& Rhodes 2010).

Changes in habitat preference and vertical shifts in position within the water column did not appear to occur, as indicated by the lack of consistent response to tidal stage (Fig. 4). The results of Connell \& Kingsford (1998) also showed little temporal variation in position within the water column. However, Samoilys \& Squire (1994) linked movements into and out of reproductive aggregation sites with lunar cycles. They also noted an increase in abundance at aggregation sites during the 3rd and 4th phases of the moon, and reproduction occurred around the new moon, when fish released gametes during strong tidal flow. According to Zeller (1998), the highest total count of Plectropomus leopardus was in aggregations during the new moon periods in October and November. In addition, Zeller (2002) also found that the upcurrent side of reefs and smaller structures were preferred, and that fish moved with changing upcurrent positions through the tidal cycle.

Previously examined movements of Plectropomus leopardus indicate site fidelity to both home ranges and aggregation sites (Zeller 1997, 1998, Zeller \& Russ 1998). Such behaviours must be considered in MPA delineation. In the present study, movements away from the aggregation site were 9 times more likely after the reproductive period. However, at OTI, fish only moved a maximum distance of $0.6 \mathrm{~km}$ from the aggregation within the lagoon (Fig. 1). In comparison, these values differ greatly from those documented by Hutchinson \& Rhodes (2010) for P. areolatus $(23 \mathrm{~km}), P$. leopardus $(5.2 \mathrm{~km})$, Epinephelus striatus $(240 \mathrm{~km})$ and E. guttatus $(33 \mathrm{~km})$. Zeller (1998) found that the distance between home ranges and aggregation sites ranged from 0.2 to $5.2 \mathrm{~km}$ $($ mean $=0.9 \pm 0.2 \mathrm{~km})$, and that movement back and forth between these sites ranged from 0.6 to $17 \mathrm{~km}$. 
In the present study, the mean distance moved by $P$. leopardus was less during the reproductive period $\left(10.63 \pm 0.13 \mathrm{~km} \mathrm{~d}^{-1}\right)$ and greater $\left(14.48 \pm 0.26 \mathrm{~km} \mathrm{~d}^{-1}\right)$ during the post-reproductive period, which contrasts with observations by Samoilys (1997a). However, Zeller \& Russ (1998) also showed that P. leopardus moved much less (mean $=0.2 \mathrm{~km} \mathrm{~d}^{-1}$ ) during reproduction. These observations probably have a bioenergetic explanation, with re-direction of resources primarily towards reproduction. During the reproductive period, movement rates may have been reduced as fish conserved energy, remained relatively aggregated and devoted bioenergetic resources to gamete production and spawning. After reproduction, movement rates may have increased and proximity to the bottom of the reef (i.e. fish depth) may also have increased as fish became more engaged in foraging activities to replace resources lost during reproduction. In our study, fish moved most in the morning segment of the post-reproductive period, and this was likely related to visually oriented foraging activity. The least amount of movement was observed during the night throughout the study, and there was no significant difference in nighttime movement between the reproductive and post-reproductive period. Zeller (1998) found that $60 \%$ of departures from aggregation sites occurred in the morning and minimal movement occurred at night. Pastor et al. (2009) observed peak hours of activity between 08:00-09:00 and 19:00-20:00 h, with decreased activity at sunset for Epinephelus marginatus in the Mediterranean. The variation in movement and distance traveled between home ranges and aggregation sites by $P$. leopardus and other species of serranids is large. In this context, general protection of all serranids may require a maximum distance of $240 \mathrm{~km}$ from aggregations to be protected; however, for $P$. leopardus a maximum distance of $5.2 \mathrm{~km}$ may be sufficient at OTI, but this may not be appropriate for other areas.

It is important to note that several fish disappeared entirely during the study, which may be related to detection efficiency within a complex reef habitat or inter-reef movement. Hutchinson \& Rhodes (2010) tested the efficiency of tag detection and found that in open water with no obstructions, detection ranges were $0.25 \mathrm{~km}$, but when fish were associated with reefs, distances dropped to $0.1 \mathrm{~km}$, and in complex coral, reception dropped to under $40 \mathrm{~m}$ with the worst detection ranges of $10-20 \mathrm{~m}$. In addition to complex coral habitat, wind, sea state and biological noise (e.g. pistol shrimp) may also interfere with detection of ultrasonic transmissions, meaning that the effects of these factors on signal detectability and orientation need to be considered to minimize directional bias and error (Zeller 1999, Farmer et al. 2013).

When considering inter-reef movements for the creation of MPAs, Zeller (1998) found that multiple aggregation sites do exist, and there was circumstantial evidence to suggest that inter-reef movements may have occurred in the present study. However, this contradicts results from Davies (1995), who found minimal movement between reefs even during reproductive periods. Zeller (1998) reported that only $31 \%$ of tagged fish returned to an aggregation, and one male utilized a spawning site $0.7 \mathrm{~km}$ away on a neighboring patch reef even though there were closer well-established aggregations. In a similar study, an individual Nassau grouper was caught at an aggregation $220 \mathrm{~km}$ away from the reef, where it was tagged in the Bahamas, although there were many other aggregations much closer (Bolden 2000). Bolden (2000) suggested that the locations of aggregations may be learned through social cues from older individuals. Evidence suggests that inter-environmental and inter-reef movements likely do occur and should be incorporated into the delineation of MPAs.

Consistent movements out of the aggregation indicate that fish were seeking one or a combination of the following: (1) better feeding conditions on the reef edge (Connell \& Kingsford 1997) due to lack of significant resources within the aggregation site (Samoilys \& Squire 1994), or (2) cleaning stations and/or social interactions with conspecifics (e.g. courting, Kingsford 2009). However, Plectropomus leopardus in the OTI lagoon remained within 2.6 ha for over $81 \mathrm{~d}$, suggesting a preference for particular smaller areas within a larger home range. Previous studies have shown that $P$. leopardus maintain a small number of sites for access to shelter and cleaning stations, and may move along the reef slope in search of prey (Samoilys 1997a, Zeller 1997). Samoilys (1997a) tracked $P$. leopardus that moved a mean distance of $2 \mathrm{~km}$, to a maximum of $7.5 \mathrm{~km}$, along the reef slope before returning to an aggregation site. Displacement experiments and observations of aggregation fidelity indicate that $P$. leopardus can and will move across the reef crest, and they have the ability to rapidly return to previously occupied areas over distances of several kilometers (C.M.B. \& M.J.K. unpubl. data). This indicates strong site fidelity and exceptional homing abilities in highly complex reef habitats.

In conclusion, although the cumulative distances moved per day were high, Plectropomus leopardus often moved within a relatively small area and had specific habitat preferences that differed across the 
reproductive and post-reproductive periods. Comparisons between $P$. leopardus and other serranids show that variation in movement is great and therefore multiple species cannot be effectively protected using similar management measures. Unless maximum movements of species (e.g. Epinephelus striatus) are used, species-specific and site-specific management plans should be developed. Therefore, to effectively protect and sustain $P$. leopardus, research on site-specific aggregations, migratory corridors and adjacent home range habitats must be conducted to determine appropriate sizes and placement of areas where $P$. leopardus could be protected from exploitation.

Acknowledgements. The authors of this study are grateful for an ARC Grant to M.J.K. and an NSERC post-doctoral research fellowship to C.M.B. Biotactic Fish \& Wildlife Research provided funding and facilities for data analysis and manuscript preparation. Special thanks to Phil Bolton, Paul Condon and Julian Hughes for assistance in the field. Brett Raven developed and wrote the code for the Biotrek program used to analyze our telemetry data. Tidal and lunar data were provided by the Commonwealth of Australia and Sydney Observatory. Thanks for the support of Konrad and Pam Beinssen (managers at OTI) during the study. We also thank Stephanie Choo-Wing, Dana Eddy, Adam Martin, Rebecca McNeil, Emily Taylor, Samantha Crowley, Barbara Piolunowska, Dan Watkins and several anonymous reviewers. All international and institutional ethics standards were followed throughout the course of this study.

\section{LITERATURE CITED}

Aguilar-Perera A, Aguilar-Dávila W (1996) A spawning aggregation of Nasau grouper Epinephelus striatus (Pisces: Serranidae) in the Mexican Caribbean. Environ Biol Fishes 45:351-361

Bohnsack JA (1982) Effects of piscivorous predator removal on coral reef fish community structure. In: Caillet GM, Simenstad CA (eds) Gutshop '81: fish food habit studies. Washington Sea Grant, Seattle, WA, p 258-267

Bolden SK (2000) Long-distance movement of a Nassau grouper (Epinephelus striatus) to a spawning aggregation in the central Bahamas. Fish Bull 98:642-645

Ceccarelli D, Ayling T (2010) Role, importance and vulnerability of top predators on the Great Barrier Reef: a review. Research Publications Series No. 105, Great Barrier Reef Marine Park Authority, Townsville

Choat JH (1968) Feeding habits and distribution of Plectropomus maculatus Serranidae at Heron Island Australia. Proc R Soc Queensl 80:13-19

Connell SD, Kingsford MJ (1997) The utility of descriptive information for assessing the impact of coral reef piscivores on their prey. Proc 8th Int Coral Reef Symp 1:999-1004

Connell SD, Kingsford MJ (1998) Spatial, temporal and habitat-related variation in the abundance of large predatory fish at One Tree Island, Australia. Coral Reefs $17: 49-57$

Cornish A, Kiwi LK (2004) Plectropomus leopardus. In: IUCN
2013. IUCN Red List of Threatened Species. Version 2013.1 Davies CR (1995) Patterns of movement of three species of coral reef fish on the Great Barrier Reef. PhD dissertation, James Cook University, Townsville

DeMartini EE (1993) modeling the potential of fishery reserves for managing Pacific coral reef fishes. Fish Bull 91:414-427

Domeier ML, Colin PL (1997) Tropical reef fish spawning aggregations: defined and reviewed. Bull Mar Sci 60: 698-726

Donaldson TJ (2002) Habitat association and depth distribution of two sympatric groupers of the genus Cephalopholis (Serranidae: Epinephelinae). Ichthyol Res 49:191-193

Eggleston DB (1995) Recruitment in Nassau grouper Epinephelus striatus: post-settlement abundance, microhabitat features, and ontogenetic habitat shifts. Mar Ecol Prog Ser 124:9-22

Eklund AM, McClellan DB, Harper DE (2000) Black grouper aggregations in relation to protected areas within the Florida Keys National Marine Sanctuary. Bull Mar Sci 63: 721-728

> Farmer NA, Ault JS, Smith SG, Franklin EC (2013) Methods for assessment of short-term coral reef fish movements within an acoustic array. Movement Ecol 1:7

Fulton E, Kault D, Mapstone B, Sheaves M (1999) Spawning season influences on commercial catch rates: computer simulations and Plectropomus leopardus, a case in point. Can J Fish Aquat Sci 56:1096-1108

Graham NAJ, Evans RD, Russ GR (2003) The effects of marine reserve protection on the trophic relationships of reef fishes on the Great Barrier Reef. Environ Conserv 30: 200-208

Hixon MA (1991) Predation as a process structuring coralreef fish communities. In: Sale PF (ed) The ecology of fishes on coral reefs. Academic Press, London, p 475-508

> Hutchinson N, Rhodes KL (2010) Home range estimated for squaretail coralgrouper, Plectropomus areolatus (Rüppell 1830). Coral Reefs 29:511-519

Jeffrey CFG, Leeworthy V, Monaco ME, Piniak G, Fonseca $M$ (eds) (2012) An integrated biogeographic assessment of reef fish populations and fisheries in Dry Tortugas: effects of no-take reserves. NOAA Tech Memo NOS NCCOS 111. Silver Spring, MD

Kingsford MJ (1992) Spatial and temporal variation in predation on reef fishes by coral trout (Plectropomus leopardus, Serranidae). Coral Reefs 11:193-198

- Kingsford MJ (2009) Contrasting patterns of reef utilization and recruitment of coral trout (Plectropomus leopardus) and snapper (Lutjanus carponotatus) at One Tree Island, southern Great Barrier Reef. Coral Reefs 28:251-264

Little LR, Smith ADM, McDonald AD, Punt AE, Mapstone BD, Pantus F, Davies CR (2005) Effects of size and fragmentation of marine reserves and fisher infringement on the catch and biomass of coral trout, Plectropomus leopardus, on the Great Barrier Reef, Australia. Fish Manag Ecol 12:177-188

Mäki-Petäys A, Muotka T, Huusko A, Tikkanen P, Kreivi P (1997) Seasonal changes in habitat use and preference by juvenile brown trout, Salmo trutta, in a northern boreal river. Can J Fish Aquat Sci 54:520-530

Manson FJ, Loneragan NR, Harch BD, Skilleter GA, Williams L (2005) A broad-scale analysis of links between coastal fisheries production and mangrove extent: a case-study for northeastern Australia. Fish Res 74:69-85

Mapstone BD, Davies CR, Little LR, Punt AE and others 
(2004) The effects of line fishing on the Great Barrier Reef and evaluation of alternative potential management strategies. CRC Reef Research Centre Technical Report, 52. CRC Reef Research Centre, Townsville

> Mclean DL, Harvey ES, Meeuwig JJ (2011) Decline in the abundance of coral trout (Plectropomus leopardus) in areas closed to fishing at the Houtman Abrolhos Islands, Western Australia. J Exp Mar Biol Ecol 406:71-78

Morris AV, Roberts CM, Hawkins JP (2000) The threatened status of groupers (Epinephelinae). Biodivers Conserv 9:919-942

Nardi K, Jones GP, Moran MJ, Cheng YW (2004) Contrasting effects of marine protected areas on the density of two exploited reef fishes at the sub-tropical Houtman Abrolhos Islands, Western Australia. Environ Conserv 31:160-168

> Nemeth RS (2005) Population characteristics of a recovering US Virgin Islands red hind spawning aggregation following protection. Mar Ecol Prog Ser 286:81-97

O'Dor RK, Aitken JP, Babcock RC, Bolden SK, Seino S, Zeller DC, Jackson GD (2001) Using radio-acoustic positioning and telemetry (RAPT) to define and assess marine protected areas (MPAs). In: Sibert J, Nielsen J (eds) Electronic tagging and tracking in marine fisheries, Vol 1. Kluwer, Dordrecht, p 147-166

Pastor J, Verdoit-Jarraya M, Astruch P, Dalias N, Pasqual JN, Saragoni G, Lenfant P (2009) Acoustic tememetry survey of the dusky grouper (Epinephelus marginatus) in the Marine Reserve of Carbere-Banyulus: information on the territoriality of this emblematic species. CR Biol 332:732-740

Pet JS, Mousa PJ, Muljadia AH, Sadovy YJ, Squire L (2005) Aggregations of Plectropomus areolatus and Epinephelus fuscoguttatus (groupers, Serranidae) in the Komodo National Park, Indonesia: monitoring and implications for management. Environ Biol Fishes 74:209-218

Queensland Government (2011) Annual status report 2010 coral reef fin fish fishery. The State of Queensland Department of Employment, Economic Development and Innovation

Rowley RJ (1994) Marine reserves in fisheries management. Aquat Conserv 4:233-254

Russ GR (1991) Coral reef fisheries: effects and yields. In: Sale PF (ed) The ecology of fishes on coral reefs. Academic Press, San Diego, CA, p 601-634

Russ GR, Alcala AC (1996a) Do marine reserves export adult fish biomass? Evidence from Apo Island, Central Philippines. Mar Ecol Prog Ser 132:1-9

Russ GR, Alcala AC (1996b) Marine reserves: rates and patterns of recovery and decline of a large predatory fish. Ecol Appl 6:947-961

Russ GR, Cheal AJ, Dolman AM, Emslie MJ and others (2008) Rapid increase in fish numbers follows creation of world's largest marine reserve network. Curr Biol 18: R514-R515

Sadovy Y, Eklund A (1999) Synopsis of biological data on the Nassau Grouper, Epinephelus striatus (Bloch, 1792), and the jewfish, E. itajara (Lichtenstein, 1822). NOAA Technical Report of the Fishery Bulletin FAO Fisheries Synop-

Submitted: March 11, 2013; Accepted: November 11, 2013 sis 157. US Department of Commerce, Seattle, WA

Samoilys MA (1997a) Periodicity of spawning aggregations of coral trout Plectropomus leopardus (Pisces: Serranidae) on the northern Great Barrier Reef. Mar Ecol Prog Ser 160:149-159

Samoilys MA (1997b) Movement in a large predatory fish: coral trout, Plectropomus leopardus (Pisces: Serranidae), on Heron Reef, Australia. Coral Reefs 16:151-158

Samoilys MA, Squire LC (1994) Preliminary observation on the spawning behaviour of coral trout, Plectropomus leopardus (Pisces: Serranidae), on the Great Barrier Reef. Bull Mar Sci 54:332-342

Sluka R, Chiappone M, Sullivan KM (1994) Comparison of juvenile grouper populations in Southern Florida and the Central Bahamas. Bull Mar Sci 54:871-880

St. John J, Russ GR, Brown IW, Squire LC (2001) The diet of the large coral reef serranid Plectropomus leopardus in two fishing zones on the Great Barrier Reef, Australia. Fish Bull 99:180-192

Syms C, Kingsford MJ (2008) Coral reef habitats and assemblages. In: The Great Barrier Reef: biology, environment and management. CSIRO Publishing, Collingwood, VIC, Australia, p 40-50

Thresher RE (1984) Reproduction in reef fishes, 1st edn. TFH Publications, Neptune City, NJ

Watson DL, Harvey ES, Kendrick GA, Nardi K, Anderson MJ (2007) Protection from fishing alters the species composition of fish assemblages in a temperate tropical transition zone. Mar Biol 152:1197-1206

Williams AJ, Currey LM, Begg GA, Murchie CD, Ballagh AC (2008) Population biology of coral trout species in eastern Torres Strait: implications for fisheries management. Cont Shelf Res 28:2129-2142

Williamson DH, Russ GR, Ayling AM (2004) No-take marine reserves increase abundance and biomass of reef fish on inshore fringing reefs of the Great Barrier Reef. Environ Conserv 31:149-159

Zeller DC (1996) Patterns of movement of Plectropomus leopardus (Serranidae) in relation to spawning aggregations and marine protected areas, as determined by ultrasonic telemetry. PhD thesis, James Cook University, Townsville

Zeller DC (1997) Home range and activity patterns of the coral trout Plectropomus leopardus (Serranidae). Mar Ecol Prog Ser 154:65-77

Zeller DC (1998) Spawning aggregations: patterns of movement of the coral trout Plectropomus leopardus (Serranidae) as determined by ultrasonic telemetry. Mar Ecol Prog Ser 162:253-263

Zeller DC (1999) Ultrasonic telemetry: application in coral reef fisheries research. Fish Bull 97:1058-1065

Zeller D (2002) Tidal current orientation of Plectropomus leopardus (Serranidae). Coral Reefs 21:183-187

Zeller DC, Russ GR (1998) Marine reserves: patterns of adult movement of the coral trout (Plectropomus leopardus (Serranidae)). Can J Fish Aquat Sci 55:917-924

Proofs received from author(s): December 10, 2013 